Original Research Paper

\title{
Inhibitory Effect of Crude Walnut Leaf Polysaccharides on Oxidative Damage of Proteins and Proliferation of SGC-7901 Cells
}

\author{
Shuqing Yang, Zhike Xie, Shuyan Yu, Ming He, Qing Liu, Haifang Xiao* and Yuanda Song \\ Colin Ratledge Center for Microbial Lipids, \\ School of Agricultural Engineering and Food Science, Shandong University of Technology, Zibo, China
}

\author{
Article history \\ Received: $30-12-2019$ \\ Revised: 24-02-2020 \\ Accepted: 20-04-2020 \\ Corresponding Author: \\ Haifang Xiao \\ Colin Ratledge Center for \\ Microbial Lipids, School of \\ Agricultural Engineering and \\ Food Science, Shandong \\ University of Technology, \\ Zibo, China \\ Email: xiaohaifang@sdut.edu.cn
}

\begin{abstract}
In this paper, we studied the inhibitory effect of crude Walnut Leaf Polysaccharides (WLP) on free radical-induced oxidative damage of proteins and anti-proliferation activity on human Gastric Cancer cells (SGC-7901). The oxidative degradation of Bovine Serum Albumin (BSA), mouse brain proteins (MBP) and Mouse Liver Proteins (MLP) induced by hydroxyl radical and alcoxyl radical was analyzed by Sodium Dodecyl Sulfate-Polyacrylamide Gel Electrophoresis (SDS-PAGE). In addition, MTT method was used to analyze the effect of WLP on cell viabilities of SGC-7901 cells. The results indicated that WLP significantly inhibited the oxidative damage of BSA induced by hydroxyl radical within the concentration range of $0.5 \sim 20 \mathrm{mg} / \mathrm{mL}$. Similar protective effects were found in hydroxyl radical-induced oxidative damage on mouse tissue proteins. WLP inhibited the oxidative damage of three protein models induced by alcoxyl radical in a dose-dependent manner. Furthermore, WLP inhibited the growth of SGC-7901 cells in time- and concentrationdependent manner. In conclusion, WLP show significant inhibitory effect on protein oxidative damage induced by hydroxyl radical and alcoxyl radical as well as anti-proliferation capacity on SGC-7901 cells.
\end{abstract}

Keywords: Walnut Leaf, Polysaccharide, Protein, Oxidative Damage, SGC-7901 Cells

\section{Introduction}

Free radicals in the body are produced during normal metabolic processes. However, the excessive accumulation of free radicals will damage the body's protein, DNA and other biological macromolecules, which will lead to diseases such as cancer and diabetes, etc. (Gao et al., 2015; Lai et al., 2010). In recent years, free radicals-induced oxidative damage of proteins has become a hot topic in human nutrition and health (El-Azem et al., 2019).

Oxidative stress are mainly produced in mitochondria of human cells and related to progressive dysfunction of mitochondria which occurred in cancer (Pecorini et al., 2020). Thus, decrease ROS levels or oxidative stress in human cells can reduce the risk of cancer. With the deep understanding of oxidative stress, antioxidant substances have attracted the attention of many researchers. Although synthetic antioxidants have been proved to be effective in the treatment of many diseases, long-term and/or overdose consumption of some synthetic antioxidants such as Butylated Hydroxyanisole (BHA) and Butylated Hydroxytoluene (BHT) may increase the risks of cancer (Seedevi et al., 2017; Xie et al., 2016). Studies have shown that foods with natural antioxidant ingredients can reduce the degree of oxidative damage in the body and decrease the risk of many diseases (Cerqueira et al., 2009; Chang et al., 2010; He et al., 2011; Palanisamy et al., 2017; Liu et al., 2018). Moreover, chemotherapy and surgery are the mainstream methods of cancer treatment, but some chemotherapy drugs have many limitations, such as limited efficacy of adverse reactions and high failure rate (Xie et al., 2013). Therefore, it is of great significance to extract and study natural active substances with antioxidant and anticancer activities from natural resources.

Several antioxidants and anticancer substances are found in nature. Among them, polysaccharides, an important source of functional food and drugs, are widely found in plants, animals and microbes etc. and possess the 
activities of anti-oxidation, immunomodulation, bacteriostasis, anti-virus, antihypertensive and anticancer (Mzoughi et al., 2018; Pan et al., 2018; Thambiraj et al., 2018; Hu et al., 2017; Li et al., 2017a; 2017b; Li and Shan, 2014; Cai et al., 2016; Romdhane et al., 2017; Teng et al., 2013). Walnut tree is a deciduous tree native to southeast Europe (You et al., 2013). Walnut fruit is one of the most common nuts in our daily life and is also considered as a natural functional food with high economic value because of its rich nutrition (Jeddou et al., 2016; Almeida et al., 2008). As we all know, the utilization of walnut is mostly in the fruit part, but the development of walnut leaves with strong functional activity is very few, which causes a great waste of resources. If the active ingredients in walnut leaves can be extracted and utilized, the economic benefits of walnut planting will be greatly improved. In traditional medicine, walnut leaf is mainly used as an astringent and preservative and has the effect of antidiarrhea, anti-inflammatory, anti-ulcer and promoting bile flow (Tapia et al., 2013). Previous studied reported that walnut leaf extract possessed the potential of antioxidation, anti-diabete and antihypertensive effects (Forino et al., 2016; Pereira et al., 2007). In addition, our previous studies found that WLP have antioxidant activities and anticancer effect on HepG2 cells (Yang et al., 2019a; 2019b). However, the antioxidant activities of WLP from the perspective of protein oxidative damage and the anticancer effect of WLP on gastric cancer cell SGC7901 are not reported.

In order to fully reveal antioxidant and anticancer activities of WLP, in this study, WLP were extracted from walnut leaves using cellulase-assisted extraction method and the oxidative degradation of BSA, MBP and MLP was induced by $\mathrm{Cu}^{2+} / \mathrm{H}_{2} \mathrm{O}_{2}$ and AAPH to assess the inhibited effect of WLP on oxidative damage of proteins. Moreover, the survival rate of SGC-7901 cells was detected by MTT colorimetry to evaluate the inhibited activity of WLP on the proliferation of gastric cancer cells.

\section{Materials and Methods}

\section{Materials}

Walnut leaves were collected from Zibo city, Shangdong Province in July 2018. WLP was extracted using cellulase assisted method as described in our previous study (Yang et al., 2019b). SD rats were purchased from Shandong University Laboratory Animal Center. The treatment of SD rats during the experiment was in accordance with the relevant regulations of animal management methods. SD rats were fed with basal feed and drank water freely at 20$22^{\circ} \mathrm{C}$ with relative humidity of $45 \%-50 \%$. BSA was obtained from Sigma (NY, USA). Human gastric cancer cells (HL-7702) were obtained from Cell Bank of Institute of Biochemistry and Cell Biology, Chinese Academy of Sciences (Shanghai, China). RPMI-1640 medium, Fetal Bovine Serum (FBS) and penicillinStreptomycin (PS) were obtained from Gibco (NY, USA). Thiazolyl blue tetrazolium bromide (MTT) was obtained from Saiguo Biotechnology Co., Ltd (Guangzhou, China). Other reagents were analytical pure. The experimental water was ultra pure water.

\section{Methods}

\section{Cellulase-Assisted Extraction of WLP}

The walnut leaves were dried naturally and then crushed and sifted, then the powder of walnut leaves and cellulase were weighed accurately in proportion and added into a certain amount of distilled water. After soaking them fully, they were immersed in a shaking tank (Yiheng, China) for $2 \mathrm{~h}$, centrifuged at $4000 \mathrm{r} / \mathrm{min}$ for $10 \mathrm{~min}$ and the supernatant was collected. Sevage reagent (chloroform: $n$-butanol $=4: 1$ ) was added to the polysaccharide solution for deproteinization and the polysaccharide and sevage reagent were mixed in a 1:1 ratio for $30 \mathrm{~min}$. The deproteinized polysaccharide solution was taken and rotated to an appropriate volume under pressure at $50^{\circ} \mathrm{C}$. Precooled anhydrous ethanol was added and placed overnight at $4^{\circ} \mathrm{C}$. WLP was obtained after precipitation was collected and dried (Zhu et al., 2014; Yang et al., 2017; Yin et al., 2018).

\section{Preparation of Histone Protein}

The brain and liver tissues of SD rats were rinsed with cold normal saline and some tissues of certain quality were cut out and put into Ripa and PMSF solution. The ice bath homogenate was centrifuged at $4^{\circ} \mathrm{C}(8000 \mathrm{r} / \mathrm{min}, 15$ $\min )$. The supernatant was tissue protein. Histoprotein concentration was determined by BCA method.

\section{Inhibition of WLP on Alkoxy Radicals-Induced Protein Oxidative Damage}

BSA solutions or tissue protein solutions with a final concentration of $0.6 \mathrm{mg} / \mathrm{mL}$ were mixed with different concentrations of WLP and bathed in water at $37^{\circ} \mathrm{C}$ for $30 \mathrm{~min}$. Then AAPH was added to the experimental group and the same volume of Phosphate Buffer (PBS, pH7.4) was used to replace AAPH in the control group. The samples were further treated in a water bath at $37^{\circ} \mathrm{C}$. SDS-PAGE electrophoresis was used to analysis the protein samples after $4 \mathrm{~h}$.

\section{Inhibition of WLP on Hydroxyl Radicals-Induced Protein Oxidative Damage}

The method has been slightly modified by reference to the previous literature (Yuan et al., 2013). WLP and protein samples were incubated the same way as above. 
$\mathrm{H}_{2} \mathrm{O}_{2}(25 \mathrm{mmol} / \mathrm{L})$ and $\mathrm{CuSO}_{4}(0.1 \mathrm{mmol} / \mathrm{L})$ solutions were added to the experimental groups and the PBS with the same volume (pH7.4) was used to replace $\mathrm{H}_{2} \mathrm{O}_{2}$ and $\mathrm{CuSO}_{4}$ in the control group. After mixed, the samples were bathed in water at $37^{\circ} \mathrm{C}$ for $90 \mathrm{~min}$, then the degree of protein oxidation was determined by SDS-PAGE.

\section{Detection of Protein Oxidative Damage}

The pre-treated samples were added with SDS loading buffer and treated at $95^{\circ} \mathrm{C}$ for $5 \mathrm{~min}$. Then, equivalent samples were taken for $10 \%$ SDS-PAGE gel electrophoresis (Thermo, USA). After $70 \mathrm{~min}$, the samples were stained with $0.1 \%$ coomassie bright blue R-250 and then the samples were decolorized with the decolorization solution. Finally, images were taken under the GelDoc XRS gel imaging system (Bio-Rad, USA) and the image band gray scale was analyzed by Image J software (Xiang et al., 2013).

\section{Cell Culture and Activity Measurement of SGC- 7901}

SGC-7901 cells were cultured in a complete RPMI1640 medium containing $10 \% \mathrm{FBS}$ and $1 \% \mathrm{PS}$ and the incubator conditions were set at $37^{\circ} \mathrm{C}$ and $\mathrm{CO}_{2}$ concentration of $5 \%$. The activity of SGC-7901 cells was determined by MTT colorimetry (Hu et al., 2017). The cultured cells were inoculated into 96-well plates at a density of $5 \times 10^{4} / \mathrm{mL}$ for $24 \mathrm{~h}$, then treated with different doses of WLP for $12 \mathrm{~h}$ and $24 \mathrm{~h}$, respectively. Then $20 \mu \mathrm{L}$ of MTT solution was added to each well and incubated at $37^{\circ} \mathrm{C}$ for $4 \mathrm{~h}$. After the unreacted dye was removed, $100 \mu \mathrm{L}$ of DMSO was added to each well. Finally, the OD value was measured using a microplate reader (Bio-Rad, USA) at $570 \mathrm{~nm}$. The survival rate of SGC-7901 cells was calculated according to the following formula:

$$
\text { The cell viability }(\%)=100 \times \frac{\text { Absorbance of experimental group }}{\text { Absorbance of blank control group }}
$$

\section{Statistical Analysis}

The statistically analysis of the results were executed by Origin 8.0 and Excel 2019.All data were indicated as the means \pm Standard Deviation (SD) and evaluated using Analysis of Variance (ANOVA). For all comparisons, a significant difference was judged to be statistically significant if $P<0.05$.

\section{Results and Discussion}

\section{Inhibitory Effect of WLP on Oxidative Damage of $B S A$}

AAPH could produce alkoxy radical after heat treatment. It can be seen from Fig. 1 that AAPH induced significant oxidative damage on BSA and the WLP in the concentration range of $0.1-2.5 \mathrm{mg} / \mathrm{ml}$ had an obvious inhibitory effect on the oxidative damage of BSA induced by alkoxy radicals $(P<0.01)$ in dosedependent manner.

$\mathrm{Cu}^{2+}$ catalyzes $\mathrm{H}_{2} \mathrm{O}_{2}$ to produce hydroxyl radicals. As can be seen from Fig. 2, the grayscale of the bands after hydroxyl radical treatment became lighter significantly $(P<0.01)$, indicating that hydroxyl radical caused oxidative damage of BSA. Compared with the $\mathrm{Cu}^{2+} / \mathrm{H}_{2} \mathrm{O}_{2}$-induced sample, the gray levels of BSA electrophoresis bands were significantly deepened after pretreatment with different concentrations of WLP $(P<0.01)$, which indicated that WLP could inhibit the oxidative damage of BSA and the higher the concentration was, the more significant the protective effect was. When the concentration of WLP was 20 $\mathrm{mg} / \mathrm{mL}$, its protective effect on BSA was as high as $94.86 \%$. These results indicated that WLP could significantly inhibit alcoxyl radical and hydroxyl radical induced BSA oxidative damage.

\section{Inhibitory Effect of WLP on Oxidative Damage of $M B P$}

Protein plays a key role in the growth and functional development of brain cells. Under the condition of oxidative stress, the balance between strong oxidants and antioxidants in the body is destroyed and a large number of free radicals are generated to induce oxidative damage of tissue proteins such as brain proteins, leading to the occurrence of brain diseases (Butterfield et al., 2001).

As can be seen from Fig. 3, $50 \mathrm{mmol} / \mathrm{L}$ of AAPH caused significant oxidative degradation of MBP. WLP at $0.5 \mathrm{mg} / \mathrm{mL}$ had no significant inhibitory effect on the oxidative damage of MBP induced by alkoxy radicals. However, the oxidative degradation degree of MBP was significantly reduced after pretreatment with $2,3.5$ and $5 \mathrm{mg} / \mathrm{mL}$ of WLP. The above results indicated that WLP with concentrations of $2-5 \mathrm{mg} / \mathrm{mL}$ had significant protective effects on alkoxy radical induced MBP oxidation.

As shown in Fig. 4, the degree of MBP oxidation induced by hydroxyl radical increased significantly compared with the blank group $(P<0.01)$. After the pretreatment of $0.01-0.1 \mathrm{mg} / \mathrm{mL}$ WLP, the gray level of hydroxyl free-radical-induced MBP bands increased significantly and the higher the concentration of WLP, the more obvious the protective effect on MBP $(P<0.01)$. When the concentration of WLP was $0.1 \mathrm{mg} / \mathrm{mL}$, the protection rate was up to $99.40 \%$. The above results indicated that WLP inhibited hydroxyl radical induced MBP oxidative damage. 


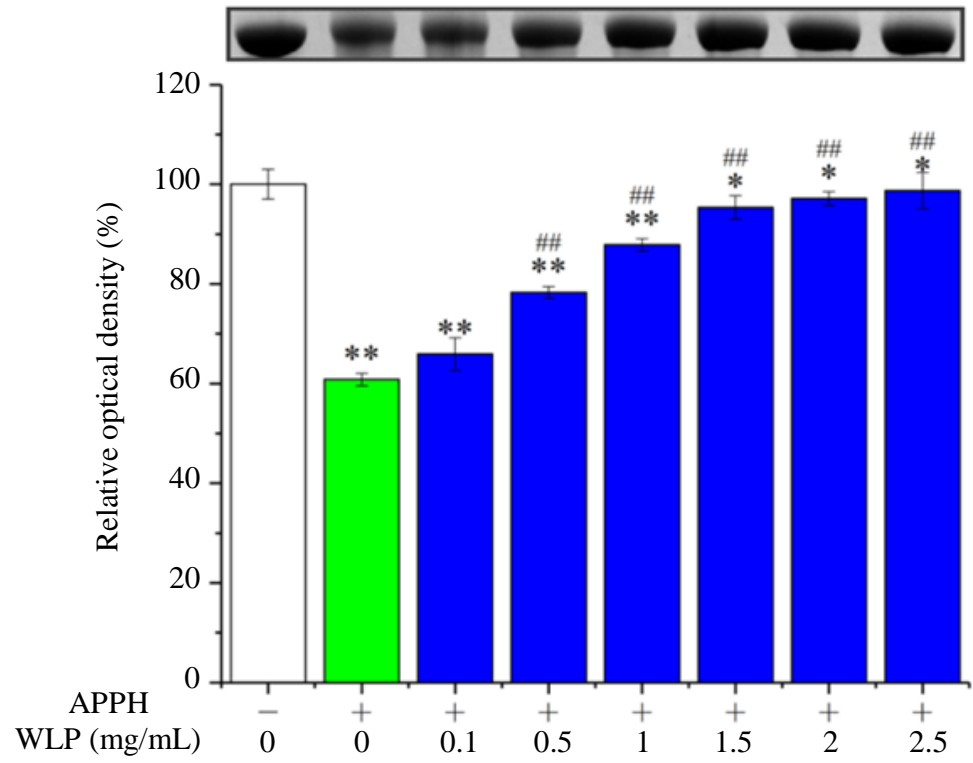

Fig. 1: Inhibitory effect of WLP on alcoxyl radical-induced oxidative damage of BSA. -. inexistent; +. existent. Compared with the blank group, *. Difference was significant $(P<0.05)$, **. Difference was extremely significant $(P<0.01)$; compared with the induction group, \#.Difference was significant $(P<0.05)$, \#\#.Difference was extremely significant $(P<0.01)$. Similarly hereinafter

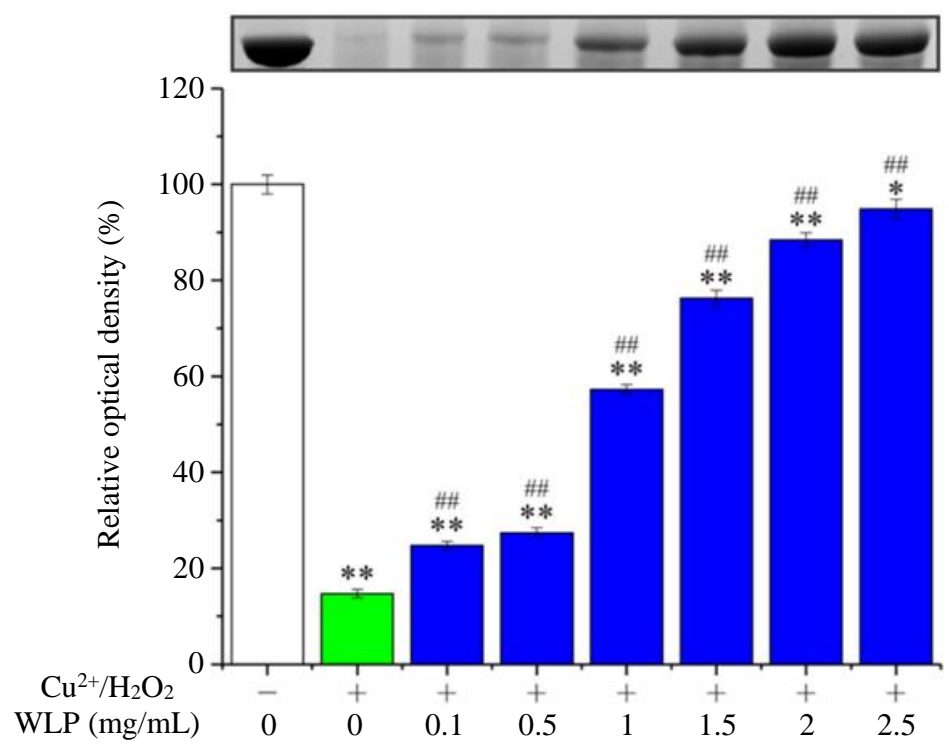

Fig. 2: Inhibitory effect of WLP on hydroxyl radical-induced oxidative damage of BSA

\section{Inhibitory Effect of WLP on Oxidative Damage of $M L P$}

The liver is an important organ involved in metabolism and plays a key role in protein synthesis. However, free radicals can easily induce protein damage in the liver and affect the health of the liver (Zhang et al., 2013).
It can be seen from Fig. 5 that WLP interfered with protein bands deepen, indicating that the concentration of WLP in the range of $0.5-2 \mathrm{mg} / \mathrm{mL}$ could effectively inhibit the MLP damage caused by alkoxy free radical and presented a concentration dependent relationship. When the concentration of WLP was up to $2 \mathrm{mg} / \mathrm{mL}$, the protective effect of MLP on MLP oxidative damage induced by alkoxy radical reached $99 \%$. The above 
results showed that WLP prevented the oxidative attack of alkoxy radicals on MLP.

As can be seen from Fig. 6, the band of histone induced by hydroxyl radical became lighter $(P<0.01)$, indicating that hydroxyl radical induced oxidative degradation of MLP. WLP with a concentration range of $0.5-10 \mathrm{mg} / \mathrm{mL}$ inhibited hydroxyl radical-induced oxidative damage of MLP in a dose dependent manner. The results showed that WLP could inhibit the oxidative degradation of MLP induced by hydroxyl free radical.

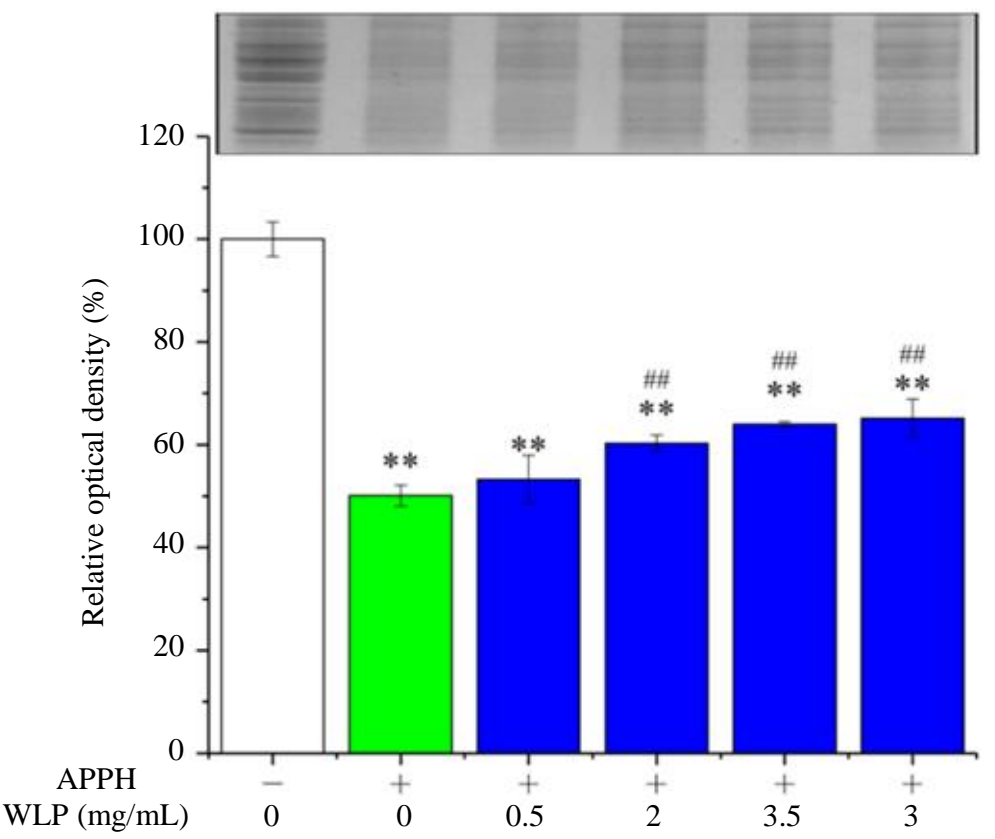

Fig. 3: Inhibitory effect of WLP on alcoxyl radical-induced oxidative damage of MBP

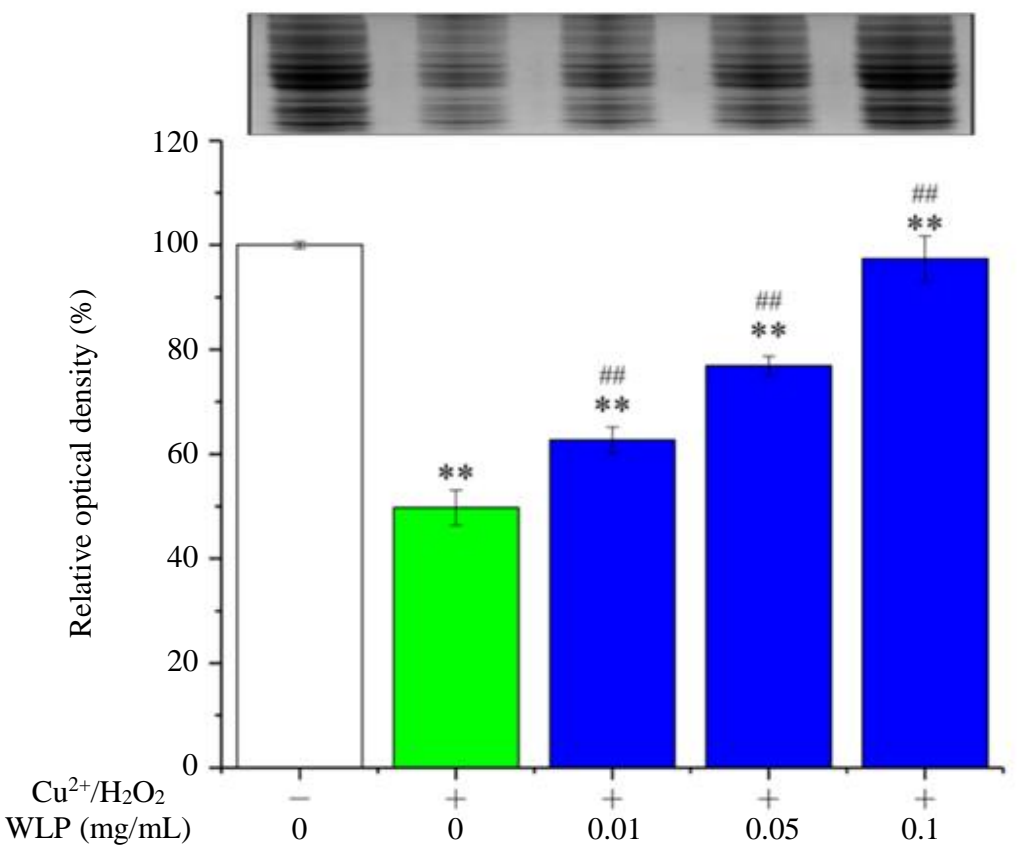

Fig. 4: Inhibiting effect of WLP on hydroxyl radical-induced oxidative damage of MBP 


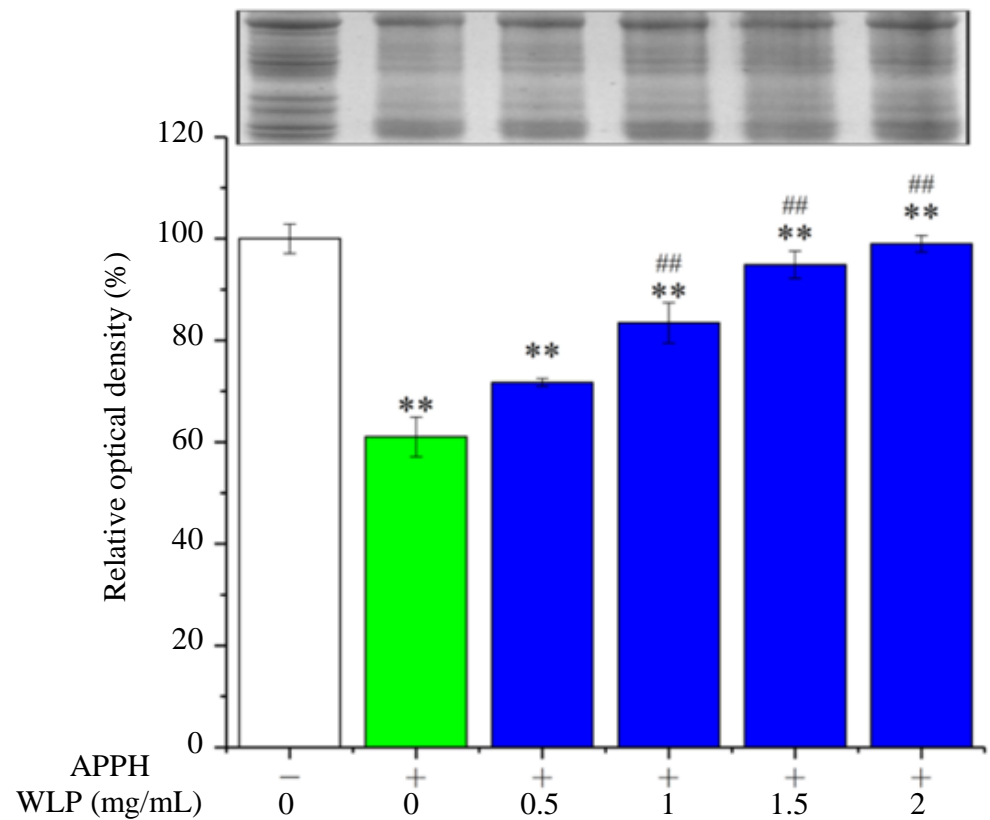

Fig. 5: Inhibitory effect of WLP on alcoxyl radical-induced oxidative damage of MLP

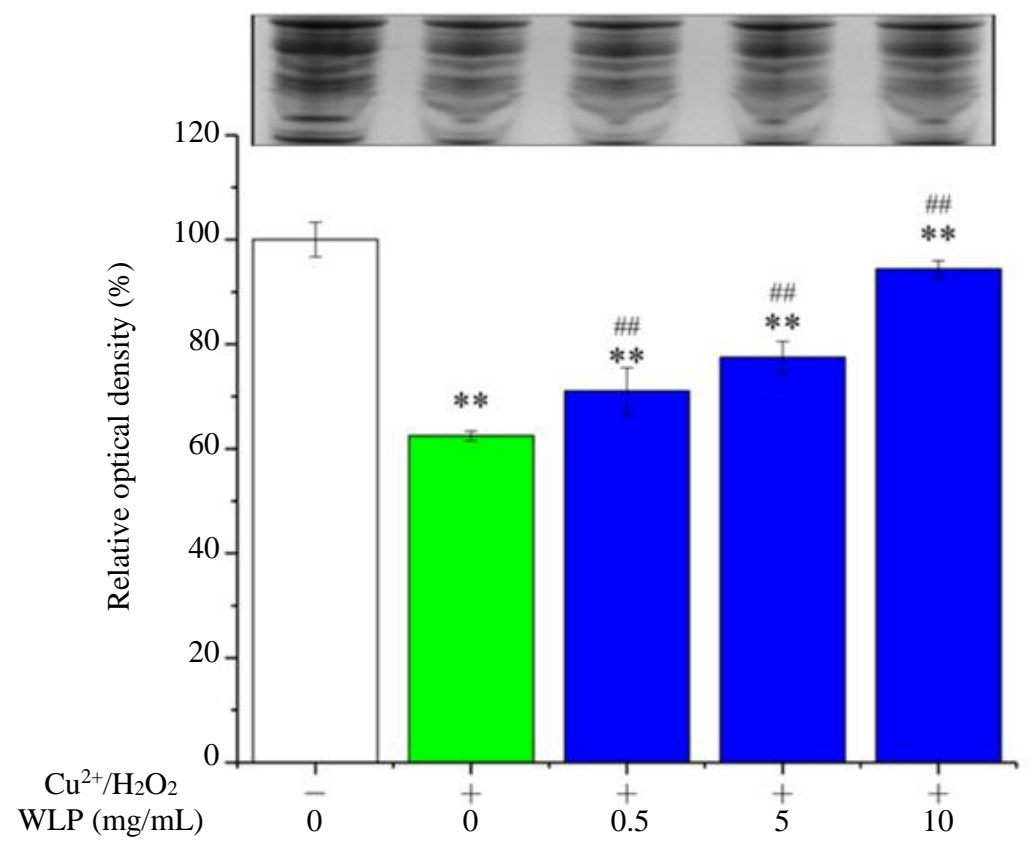

Fig. 6: Inhibitory effect of WLP on hydroxyl radical-induced oxidative damage of MLP

\section{Inhibitory Effect of WLP on SGC-7901 Cells}

The inhibitory effect of WLP on cell viability of SGC7901 cells was shown in Fig. 7. WLP displayed obvious inhibitory activity on human gastric cancer cell SGC7901. When the amount of additive was $9 \mathrm{mg} / \mathrm{mL}$, the antiproliferation activity of polysaccharide increased and the cell survival rate decreased significantly. Compared with $12 \mathrm{~h}$, the activity of SGC-7901 cells cultured with WLP for $24 \mathrm{~h}$ was weaker. The results showed that the growth of SGC-7901 cells could be inhibited by WLP in a concentration and time-dependent manner. 


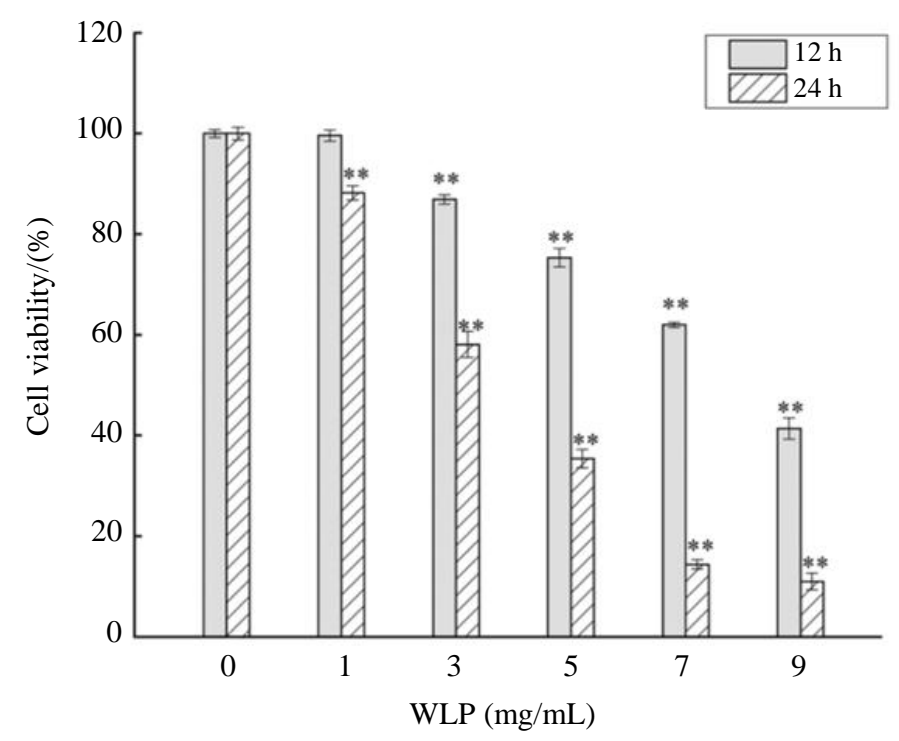

Fig. 7: Inhibitory effect of WLP on cell viability of SGC-7901 cells

\section{Conclusion}

In this paper, the antioxidant activity of WLP was investigated from the perspective of biomacromolecule. Our results proved that WLP significantly inhibited the oxidative damage of proteins (BSA, MBP and MLP) in hydroxyl radical and alkoxy radical induced systems. Moreover, this work preliminarily confirmed that WLP could reduce the cell viability of human gastric cancer SGC-7901 cells in concentration- and time-dependent manners. This study provides a basis for evaluating the antioxidant and anticancer activities of WLP and give ideas for the comprehensive utilization of agricultural waste walnut leaves.

\section{Acknowledgement}

This work was supported by SDUT and Zibo City Integration Development Project (2017ZBXC004) and Shandong Provincial Natural Science Foundation, China (No. ZR2014CQ002). Therefore, we are grateful for the funding and support of this research.

\section{Funding Information}

This work was supported by SDUT \& Zibo City Integration Development Project (2017ZBXC004) and Shandong Provincial Natural Science Foundation, China (No. ZR2014CQ002).

\section{Author's Contributions}

Shuqing Yang: Participated in the whole experiment process and also contributed to the interpretation of the results and manuscript preparation.
ZhikeXie, Shuyan Yu and Ming He: Participated in part of the experimental design.

Qing Liu: Ameliorated the manuscript.

Haifang Xiao: Contributed to the study design, the interpretation of the results and manuscript preparation.

Yuanda Song: Contributed to the guidance of experimental design and ameliorated the manuscript.

\section{Ethics}

This article is original and contains unpublished material. The corresponding author confirms that all of the other authors have read and approved the manuscript and no ethical issues involved.

\section{References}

Abdallah, I.B., N. Tlili, E. Martinez-Force, A.G.P. Rubio and M.C. Perez-Camino et al., 2015. Content of carotenoids, tocopherols, sterols, triterpenic and aliphatic alcohols and volatile compounds in six walnuts (Juglans regia L.) varieties. Food Chem., 173: 972-978.

DOI: 10.1016/j.foodchem.2014.10.095

Almeida, I.F., E. Fernandes, J.L.F.C. Lima, P.C. Costa and M.F. Bahia, 2008. Walnut (Juglans regia) leaf extracts are strong scavengers of pro-oxidant reactive species. Food Chem., 106: 1014-1020.

DOI: 10.1016/j.foodchem.2007.07.017

Butterfield, D.A., J. Drake, C. Pocernich and A. Castegna, 2001. Evidence of oxidative damage in Alzheimer's disease brain: central role for amyloid $\beta$-peptide. Trends Molecular Med., 7: 548-554. DOI: $10.1016 / \mathrm{S} 1471-4914(01) 02173-6$ 
Cai, W., H. Xu, L. Xie, J. Sun and T. Sun et al., 2016. Purification, characterization and in vitro anticoagulant activity of polysaccharides from Gentianascabra Bunge roots. Carbohydr. Polym., 140: 308-313. DOI: 10.1016/j.carbpol.2015.12.054

Cerqueira, M.A., A.C. Pinheiro, B.W.S. Souza, Á.M.P. Lima and C. Ribeiro et al., 2009. Extraction, purification and characterization of galactomannans from non-traditional sources. Carbohydr. Polym., 75: 408-414. DOI: 10.1016/j.carbpol.2008.07.036

Chang, S.C., B.Y. Hsu and B.H. Chen, 2010. Structural characterization of polysaccharides from Zizyphus jujuba and evaluation of antioxidant activity. Int. J. Biol. Macromol., 47: 445-453.

DOI: 10.1016/j.ijbiomac.2010.06.010

El-Azem, N., M. Pulido-Moran, C.L. Ramirez-Tortosa, J.L. Quiles and F.E. Cara et al., 2019. Modulation by hydroxytyrosol of oxidative stress and antitumor activities of paclitaxel in breast cancer. Eur. J. Nutr., 58: 1203-1211. DOI: $10.1007 / \mathrm{s} 00394-018-1638-9$

Forino, M., P. Stiuso, S. Lama, P. Ciminiello and G.C. Tenore et al., 2016. Bioassay-guided identification of the antihyperglycaemic constituents of walnut (Juglans regia) leaves. J. Funct. Foods, 26: 731-738. DOI: $10.1016 /$ j.jff.2016.08.053

Gao, J., T. Zhang, Z.Y. Jin, X.M. Xu and J.H. Wang et al., 2015. Structural characterisation, physicochemical properties and antioxidant activity of polysaccharide from Lilium lancifolium Thunb. Food Chem., 169: 430-438. DOI: 10.1016/j.foodchem.2014.08.016

He, L., P. Ji and X.G. Gong, W. Li and J. Cheng et al., 2011. Physico-chemical characterization, antioxidant and anticancer activities in vitro of a novel polysaccharide from Melia toosendan Sieb. Et Zucc fruit. Int. J. Biol. Macromol., 49: 422-427. DOI: 10.1016/j.ijbiomac.2011.05.028

Hu, Y., J. Zhang, L. Zou, C. Fu and P. Li et al., 2017. Chemical characterization, antioxidant, immuneregulating and anticancer activities of a novel bioactive polysaccharide from Chenopodium quinoa seeds. Int. J. Biol. Macromol., 99: 622-629.

DOI: 10.1016/j.ijbiomac.2017.03.019

Jeddou, K.B., F. Chaari, S. Maktouf, O. Nouri-Ellouz and C.B. Helbert et al., 2016. Structural, functional and antioxidant properties of water-soluble polysaccharides from potatoes peels. Food Chem., 205: 97-105. DOI: 10.1016/j.foodchem.2016.02.108

Lai, F.Q., L. Wen, H. Li, H. Wu and X. Li, 2010. Antioxidant activities of water-soluble polysaccharide extracted from mung bean (Vigna radiata $\mathrm{L}$.) hull with ultrasonic assisted treatment. Carbohydr. Polym., 81: 323-329.

DOI: 10.1016/j.carbpol.2010.02.011
Li, C., X. Li, L. You, X. Fu and R.H. Liu, 2017a. Fractionation, preliminary structural characterization and bioactivities of polysaccharides from Sargassum pallidum. Carbohydr. Polym., 155: 261-270. DOI: 10.1016/j.carbpol.2016.08.075

Li, S. and N.P. Shan, 2014. Antioxidant and antibacterial activities of sulphated polysaccharides from Pleurotus eryngii and Streptococcus thermophilus ASCC 1275. Food Chem., 165: 262-270. DOI: 10.1016/j.foodchem.2014.05.110

Li, S., A. Gao, S. Dong, Y. Chen and S. Sun et al., 2017b. Purification, antitumor and immunomodulatory activity of polysaccharides from soybean residue fermented with Morchella esculenta. Int. J. Biol. Macromol., 96: 26-34.

DOI: 10.1016/j.ijbiomac.2016.12.007

Liu, Q., X. Ge, L. Chen, D. Cheng and Z. Yun et al., 2018. Purification and analysis of the composition and antioxidant activity of polysaccharides from Helicteres angustifolia L. Int. J. Biol. Macromol., 107: 2262-2268.

DOI: 10.1016/j.ijbiomac.2017.10.095

Mzoughi, Z. M.A. Chaouch, K.M. Hammi, J. Hafsa and D. Le Cerf et al., 2018. Optimization of antioxidant and antiglycated activities of polysaccharides from Arthrocnemum indicum leaves. Int. J. Biol. Macromol., 113: 774-782.

DOI: $10.1016 /$ j.ijbiomac.2018.03.008

Pan, X.X., J.H. Tao, S. Jiang, Y. Zhu and D.W. Qian et al., 2018. Characterization and immunomodulatory activity of polysaccharides from the stems and leaves of Abelmoschus manihot and a sulfated derivative. Int. J. Biol. Macromol., 107: 9-16. DOI: 10.1016/j.ijbiomac.2017.08.130

Palanisamy, S., M. Vinosha, T. Marudhupandi, P. Rajasekar and N.M. Prabhu, 2017. Isolation of fucoidan from Sargassum polycystum brown algae: Structural characterization, in vitro antioxidant and anticancer activity. Int. J. Biol. Macromol., 102: 405-412. DOI: 10.1016/j.ijbiomac.2017.03.182

Pecorini, S., L. Gibellini, S. De Biasi, E. Bianchini and M. Nasi et al., 2020. Mitochondria, Oxidative Stress, Cancer and Aging. In: Geriatric Oncology, Extermann, M. (Ed.), Springer, Cham, pp: 183-204.

Pereira, J.A., I. Oliveira, A. Sousa, P. Valentao and P.B. Andrade et al., 2007. Walnut (Juglans regia L.) leaves: Phenolic compounds, antibacterial activity and antioxidant potential of different cultivars. Food Chem. Toxicol., 45: 2287-2295. DOI: 10.1016/j.fct.2007.06.004

Romdhane, M.B., A. Haddar, I. Ghazala, K.B. Jeddou and C.B. Helbert et al., 2017. Optimization of polysaccharides extraction from watermelon rinds: Structure, functional and biological activities. Food Chem., 216: 355-364.

DOI: $10.1016 /$ j.foodchem.2016.08.056 
Seedevi, P., M. Moovendhan, S. Viramani and A. Shanmugam, 2017. Bioactive potential and structural chracterization of sulfated polysaccharide from seaweed (Gracilaria corticata). Carbohydr. Polym., 155: 516-524. DOI: 10.1016/j.carbpol.2016.09.011

Tapia, M.I., J.R. Sánchez-Morgado, J. García-Parra, R. Ramírez and T. Hernández et al., 2013. Comparative study of the nutritional and bioactive compounds content of four walnut (Juglans regia L.) cultivars. J. Food Com. Analys., 31: 232-237. DOI: 10.1016/j.jfca.2013.06.004

Teng, Z., L. Qian and Y. Zhou, 2013. Hypolipidemic activity of the polysaccharides from Enteromorpha prolifera. Int. J. Biol. Macromol., 62: 254-256.

DOI: 10.1016/j.ijbiomac.2013.09.010

Thambiraj, S.R., M. Phillips, S.R. Koyyalamudi and N. Reddy, 2018. Yellow lupin (Lupinus luteus L.) polysaccharides: Antioxidant, immunomodulatory and prebiotic activities and their structural characterisation. Food Chem., 267: 319-328.

DOI: 10.1016/j.foodchem.2018.02.111

Xiang, Q.S., X. Meng and Y. Qiao, 2013. Effect of carnosic acid on free radical-mediated oxidative damage to proteins. Food Sci., 34: 281-284.

Xie, J.H., X. Liu, M.Y. Shen, S.P. Nie and H. Zhang et al., 2013. Purification, physicochemical characterisation and anticancer activity of a polysaccharide from Cyclocarya paliurus leaves. Food Chem., 136: 1453-1460. DOI: 10.1016/j.foodchem.2012.09.078

Xie, J.H., W. Tang, M.L. Jin, J.E. Li and M.Y. Xie, 2016. Recent advances in bioactive polysaccharides from Lycium barbarum L., Zizyphus jujuba Mill, Plantago spp. and Morus spp.: Structures and functionalities. Food Hydrocoll., 60: 148-160. DOI: 10.1016/j.foodhyd.2016.03.030

Yang, S., Y. Li, D. Jia, K. Yao and W. Liu, 2017. The synergy of Box-Behnken designs on the optimization of polysaccharide extraction from mulberry leaves. Ind. Crop. Prod., 99: 70-78.

DOI: $10.1016 /$ j.indcrop.2017.01.024
Yang, S.Q., H.F. Xiao and S.Y. Yu, 2019. Inhibition effect of walnut leaf polysaccharide on HepG2 cells in vitro. Am. J. Biochem. Biotechnol., 15: 179-189. DOI: 10.3844/ajbbsp.2019.179.189

Yang, S.Q., H.F. Xiao and S.Y. Yu, 2019. Optimization for the extraction of polysaccharide from walnut (Juglans regia L.) leaves: Antioxidant activities in vitro. Am. J. Biochem. Biotechnol., 15: 163-178. DOI: 10.3844/ajbbsp.2019.163.178

Yin, C., X. Fan, Z. Fan, D. Shi and H. Gao, 2018. Optimization of enzymes-microwave-ultrasound assisted extraction of Lentinusedodes polysaccharides and determination of its antioxidant activity. Int. J. Biol. Macromol., 111: 446-454. DOI: 10.1016/j.ijbiomac.2018.01.007

Yuan, L., Y.C. Wu and X.M. Ren, 2013. Comparison of antioxidant activities and cytotoxicity in HepG2 cells of orientin and isoorientin. J. Food Sci. Tec., 31: 21-27.

You, L., Q. Gao, M. Feng, B. Yang and J. Ren et al., 2013. Structural characterisation of polysaccharides from Tricholoma matsutake and their antioxidant and antitumour activities. Food Chem., 138: 2242-2249. DOI: 10.1016/j.foodchem.2012.11.140

Zhang, Y.F., G.G. Liu, Q. Liu and X.B. Liu, 2013. Inhibitory effect of eriodictyol on free radicalinduced damage to biological macromolecules and its cytotoxicity on HepG2 cells. Food Sci., 34: 126-130. DOI: 10.7506/spkx1002-6630-201317028

Zhu, Y., Q. Li, G. Mao, Y. Zou and W. Feng et al., 2014. Optimization of enzyme-assisted extraction and characterization of polysaccharides from Hericium erinaceus. Carbohydr. Polym., 101: 606-613. DOI: 10.1016/j.carbpol.2013.09.099 